\title{
Mitochondrial Contribution to Parkinson's Disease Pathogenesis
}

\author{
Anthony H. V. Schapira and Matthew Gegg \\ Department of Clinical Neurosciences, UCL Institute of Neurology, Rowland Hill Street, London NW3 2PF, UK \\ Correspondence should be addressed to Anthony H. V. Schapira, a.schapira@medsch.ucl.ac.uk
}

Received 1 December 2010; Revised 17 February 2011; Accepted 23 February 2011

Academic Editor: David K. Simon

Copyright () 2011 A. H. V. Schapira and M. Gegg. This is an open access article distributed under the Creative Commons Attribution License, which permits unrestricted use, distribution, and reproduction in any medium, provided the original work is properly cited.

\begin{abstract}
The identification of the etiologies and pathogenesis of Parkinson's disease (PD) should play an important role in enabling the development of novel treatment strategies to prevent or slow the progression of the disease. The last few years have seen enormous progress in this respect. Abnormalities of mitochondrial function and increased free radical mediated damage were described in post mortem PD brain before the first gene mutations causing familial PD were published. Several genetic causes are now known to induce loss of dopaminergic cells and parkinsonism, and study of the mechanisms by which these mutations produce this effect has provided important insights into the pathogenesis of PD and confirmed mitochondrial dysfunction and oxidative stress pathways as central to PD pathogenesis. Abnormalities of protein metabolism including protein mis-folding and aggregation are also crucial to the pathology of PD. Genetic causes of PD have specifically highlighted the importance of mitochondrial dysfunction to PD: PINK1, parkin, DJ-1 and most recently alpha-synuclein proteins have been shown to localise to mitochondria and influence function. The turnover of mitochondria by autophagy (mitophagy) has also become a focus of attention. This review summarises recent discoveries in the contribution of mitochondrial abnormalities to PD etiology and pathogenesis.
\end{abstract}

\section{Introduction}

Mitochondria are ubiquitous organelles, critical for cell survival and for correct cellular function [1]. Furthermore, they play an important role in mediating cell death by apoptosis and in determining their own destruction by mitophagy. Mitochondria are recognised to play an important role in neurodegenerative disorders. This may be a consequence of a primary mutation of mitochondrial DNA (mtDNA), for example, the A3243G mutation-a cause of myopathy, encephalopathy, lactic acidosis, and stroke-like episodes (MELAS), a mutation of a nuclear gene regulating mtDNA, for example, the mtDNA depletion syndromes, a nuclear gene encoding a mitochondrial protein, for example, frataxin in Friedreich's ataxia, secondary effects of disordered cell metabolism, for example, free radical stress, or environmental toxin exposure $[2,3]$. This review will focus on the contribution of mitochondrial pathology to the pathogenesis of Parkinson's disease (PD), and it is notable that the mitochondrial involvement covers the entire etiological spectrum detailed above.

The first report of a mitochondrial defect in PD identified deficiency of complex I activity in substantia nigra compared to age-matched controls [4] and was followed by reports of mitochondrial defects in skeletal muscle, platelets, and lymphoblasts in a proportion of cases (see [5] for review). The mitochondrial deficiency within the brain appeared to be confined to the nigra $[6,7]$ although other reports have identified defects in the frontal cortex [8]. These mitochondrial abnormalities, identified in pathologically confirmed, apparently sporadic PD, were seen against a background of increased oxidative stress and elevated brain iron levelsand emphasised the importance of interconnecting pathways even at this early stage [9-14]. It was a fortuitous accident of timing that these observations of abnormal mitochondrial metabolism in PD were being made when important insights were gained into mitochondrial diseases by identification of mutations of mtDNA.

\section{Mitochondrial Diseases and Parkinsonism}

Primary mutations of mtDNA, as opposed to, for instance mutations secondary to a nuclear housekeeping gene, rarely manifest with parkinsonism $[15,16]$. In part this may be a result of regional distribution of the mutation 
with a relatively lower level in nigral cells (although this has never been investigated), or alternatively, related to better physiological compensatory mechanisms in the younger patient, that is, those that usually manifest with the encephalomyopathies. In any event, tissue specificity of an ubiquitously expressed mutation remains common in mitochondrial disorders and is poorly explained, but may in part be related to the dependence of a tissue on high energy demands, for example, brain and muscle. Inherited mtDNA-mediated defects of complex I usually manifest with encephalomyopathic features rather than parkinsonism $[17,18]$, as do other inherited primary specific respiratory chain defects, for example, affecting complex IV [19, 20].

Mutations of mtDNA polymerase gamma (POLG) are a recognised cause of parkinsonism, usually, but not always, preceded by ophthalmoplegia and are often associated with a peripheral neuropathy [21-23]. These cases have multiple deletions of mtDNA, sometimes with mtDNA depletion, and usually exhibit ragged red fibres in muscle biopsies. They have reduced dopamine transporter density by single photon emission tomography scanning, respond well to levodopa, and have Lewy bodies at postmortem. Patients with POLG mutations can also present with other phenotypes including childhood onset liver failure, myopathy, and renal disease $[24,25]$. Mutations of POLG in sporadic PD are rare [26, 27].

Mutations of mtDNA may be inherited or somatic. Somatic mutations of mtDNA are known to develop with aging and are thought to represent cumulative damage due to excess exposure to free radicals [28]. The mitochondrial genome resides in the matrix, probably in close proximity to the inner mitochondrial membrane, a site of high superoxide ion production. Initial studies did not demonstrate any increase in deleted mtDNA genomes in pathologically proven PD [29]. However, quantitation of deleted mtDNA molecules in individual nigral neurons showed a significant rise with age [30], and this appeared to be increased in parkinsonian brains [31]. This may be the result of the enhanced oxidative stress in the nigra in these brains. Nevertheless, the neurons with the highest load of deleted mtDNA expressed a mitochondrial defect in the form of cytochrome oxidase deficiency, indicating that the deleted mtDNA population did have a functional effect [31]. Mitochondria have an important role in calcium homeostasis. Prominent calcium influx occurs in nigral dopaminergic neurons via L-type channels and is a phenomenon not shared by neighbouring dopaminergic neuronal populations, which are much less affected in PD [32]. In a DJ-1 knockout mouse model this created oxidative stress and resulted in increased oxidation of mitochondrial proteins specific to vulnerable nigral dopaminergic neurons [33].

Although the potential contribution of mtDNA to respiratory chain deficiency in PD has received support from cybrid studies [34-37] no abnormality of this genome has been consistently identified in PD patients.

\section{PARK Genes and Mitochondria}

There remains a debate as to whether the parkinsonism caused by these genes is phenotypically equivalent to "idiopathic" PD or not. In many respects this is a sterile argument given the phenotypic spectrum in idiopathic PD itself. Furthermore, mutations of several of these genes have been identified in patients who satisfy the Queen Square Brain Bank criteria for PD. The real point is that these gene mutations cause dopaminergic nigrostriatal cell death. The proteins encoded by the PINK1, parkin, and DJ-1 genes can translocate to mitochondria and influence function within that organelle, although this does not exclude additional activities in other cell compartments.

3.1. PINK1. Recessive mutations in PINK1 (Park6) were found to be responsible for a familial form of earlyonset parkinsonism, previously mapped to chromosome 1p36 [38]. PINK1 protein has a mitochondrial targeting sequence at its $\mathrm{N}$-terminus and has been shown to have an intramitochondrial location, although in which compartment(s) remains uncertain. Several reports have demonstrated abnormal mitochondrial function in models of PINK1 knockout and in patients with PINK1 mutations including defective oxidative phosphorylation, increased free radical damage and reduced mitochondrial levels [39-45].

Several of the reported mutations of PINK1 are located in the kinase domain $[38,46-48]$ and altered phosphorylation of target proteins probably represents a key pathogenic mechanism. The phosphorylation of mitochondrial proteins is considered pivotal to the regulation of respiratory activity in the cell and to signalling pathways leading to apoptosis, as well as for other vital mitochondrial processes. The generation of monoclonal antibodies to respiratory chain subunits $[49,50]$ has enabled the demonstration that a number of the subunits are phosphorylated, including several subunits of complex I [51-54].

3.2. Parkin. Parkin (Park2) gene mutations were first identified in autosomal recessive juvenile onset parkinsonism (ARJPD) [55]. Pathologically there is dopaminergic cell loss in the substantia nigra pars compacta and locus ceruleus, but Lewy bodies are rarely seen [56-58]. Patients carry deletions or point mutations in various parts of the parkin gene [59, 60]. The relevance of parkin mutations to idiopathic PD has been highlighted by the identification of parkin mutations in apparently sporadic cases of PD and by the description of Lewy bodies in parkin positive patients with later onset disease than ARJPD $[61,62]$.

Parkin protein functions as an E3 ligase, ubiquitinating proteins for destruction by the proteasome $[63,64]$ or lysosome [65]. Parkin knockout mice have decreased striatal mitochondrial respiratory chain function and reduced respiratory chain activity [66]. Parkin knockout flies developed muscle pathology, mitochondrial abnormalities, and apoptotic cell death [67]. Overexpression of parkin in PC12 cells indicated that it is associated with the mitochondrial outer membrane [68]. Parkin mutation positive patients have decreased lymphocyte complex I activity [69]. Fibroblasts from parkin mutation positive patients also exhibit decreased complex I activity and complex I-linked ATP production $[70,71]$. 
3.3. DJ-1. Mutations of DJ-1 are a rare cause of familial PD. This protein is located in the cytosol, nucleus, and mitochondria but under conditions of oxidative stress preferentially partitions to the mitochondrial matrix and intermembranous space to mediate a protective effect [72]. This protection may also be an effect of mRNA regulation and increased translation under conditions of oxidative stress [73-75]. DJ1 knockout mice downregulated uncoupling proteins 4 and 5, impaired calcium-induced uncoupling and increased oxidant damage [76]. DJ-1 is thought to have a protective role in reducing protein misfolding and aggregation that may be a consequence of oxidative stress and so has been reported to reduce alpha-synuclein aggregation [77].

3.4. Alpha-Synuclein. Point mutations in the alpha-synuclein (Park1) gene [78, 79] and more recently multiplications of the wild-type gene have been described as causes of familial PD. A triplication of the gene was identified in a large autosomal dominant kindred with $\mathrm{PD}$ and tremor [80] and duplication of the gene was found in one of 42 familial probands of early onset PD [81]. A further alphasynuclein point mutation $(\mathrm{E} 46 \mathrm{~K})$ has been reported in an autosomal dominant family with parkinsonism and Lewy body dementia [82]. Alpha-synuclein is a major component of Lewy bodies in idiopathic, apparently sporadic PD [83].

Alpha-synuclein protein is predominantly cytosolic, but a fraction has been identified in mitochondria [84], appears to interact directly with mitochondrial membranes, including at the neuronal synapse [85], and to inhibit complex I in a dose dependent manner that reflects the brain regional expression of alpha-synuclein [86, 87]. Alphasynuclein has also been shown to reduce ATP synthesis and mitochondrial membrane potential, although in one study alpha-synuclein did not affect respiratory chain activity or membrane potential $[88,89]$. Mitochondrial abnormalities of structure and function have been observed in transgenic mice over-expressing mutant alpha-synuclein [90]. Alphasynuclein undergoes an important posttranslational modification with phosphorylation at serine 129 [91], and it would be interesting to determine whether this might influence the effect of the protein on mitochondrial function.

\section{Mitochondrial Dynamics and Mitophagy}

Abnormal mitochondrial morphology and changes in mitochondrial dynamics have been reported for PINK1, parkin, DJ-1, and alpha-synuclein in a variety of cell and animal models [70, 89, 92-98]. These events could be due to direct effects on mitochondrial fission and fusion [89, 94, 97, 98], be secondary to deficiencies in oxidative phosphorylation [86], and/or be related to impaired mitochondrial turnover [99].

Recent studies have demonstrated that PINK1 together with parkin play a vital role in the turnover of mitochondria mitophagy $[96,98,100,101]$. Parkin translocates from the cytosol to the mitochondrion in response to a fall in mitochondrial membrane potential [102]. Recent data suggest that this is preceded by phosphorylation of parkin by PINK1 [103]. Parkin translocation to depolarised mitochondria is abolished in PINK1 knockout mouse embryonic fibroblasts (MEFS). Transfection of these MEFS with wild-type PINK1 restored parkin translocation [104]. However, transfection of kinase-dead PINK1 could not restore mitophagy suggesting that PINK1 recruits parkin to mitochondria by a kinase pathway. Parkin and PINK1 involvement in mitophagy includes the ubiquitination of mitofusin 1 and 2 ( $\mathrm{mfn} 1$ and 2) by parkin [105, 106]. Recently DJ-1 has also been implicated in mitophagy $[92,107]$. The increased oxidative stress as a result of DJ-1 deficiency has been suggested as a cause. Data also suggests that DJ-1 works in a parallel pathway to PINK1 and parkin [107, 108].

HtrA2 is a mitochondrial protease thought to be involved in the turnover of mitochondrial proteins. The phosphorylation of HtrA2 is dependent on PINK1, probably via a kinase cascade, rather than as a direct substrate [109]. Mutations in the HtrA2 gene are a possible rare cause of PD $[110,111]$. The mitochondrial chaperone TRAP1 has been shown to be a direct substrate of PINK1 [112]. These data suggest that PINK1 might be involved in the regulation of mitochondrial proteins as well as mitochondria as a whole.

Thus, quality control of mitochondria may play an important role in PD pathogenesis if the essential clearance of defective mitochondria is impaired and damaged mitochondria accumulate, utilising substrate and generating excess superoxide radicals. The recent description of reduced autophagy protein expression in PD nigra and amygdala may mirror defects of mitophagy [113]. Defective trafficking of mitochondria between cell compartments may be an additional consequence of impaired fission fusion and in turn may contribute to regional cellular dysfunction such as at the synapse.

\section{Conclusion}

Since the discovery of mitochondrial dysfunction in PD, a very large body of evidence has accrued to confirm that this organelle plays an important part in pathogenesis. Mitochondrial toxins have been used to induce dopaminergic cell death [114-116] and environmental exposure to toxins can increase the risk for parkinsonism [117]. The familial causes of parkinsonism/PD function in pathways that influence mitochondrial function directly or indirectly. This is not to aver that mitochondrial dysfunction is the cause of $\mathrm{PD}$, but rather to suggest that it is a critical feature and one worthy of further investigation, particularly in relation to the development of interventions to modify the course of PD. Indeed, several studies have been performed using agents that influence mitochondrial function [118-120].

\section{Acknowledgments}

The authors' work described in this study is supported by a Medical Research Council and Wellcome Trust Strategic Award, Parkinson's UK, and the Kattan Trust. 


\section{References}

[1] A. H. Schapira, "Mitochondrial disease," Lancet, vol. 368, no. 9529, pp. 70-82, 2006.

[2] J. V. Leonard and A. H. V. Schapira, "Mitochondrial respiratory chain disorders-I: mitochondrial DNA defects," Lancet, vol. 355, no. 9200, pp. 299-304, 2000.

[3] J. V. Leonard and A. H. V. Schapira, "Mitochondrial respiratory chain disorders-II: neurodegenerative disorders and nuclear gene defects," Lancet, vol. 355, no. 9201, pp. 389-394, 2000.

[4] A. H. V. Schapira, J. M. Cooper, D. Dexter, P. Jenner, J. B. Clark, and C. D. Marsden, "Mitochondrial complex I deficiency in Parkinson's disease," Lancet, vol. 1, no. 8649, p. $1269,1989$.

[5] A. H. V. Schapira, "Evidence for mitochondrial dysfunction in Parkinson's disease- a critical appraisal," Movement Disorders, vol. 9, no. 2, pp. 125-138, 1994.

[6] A. H. V. Schapira, J. M. Cooper, D. Dexter, J. B. Clark, P. Jenner, and C. D. Marsden, "Mitochondrial Complex I deficiency in Parkinson's disease," Journal of Neurochemistry, vol. 54, no. 3, pp. 823-827, 1990.

[7] A. H. V. Schapira, V. M. Mann, J. M. Cooper et al., "Anatomic and disease specificity of NADH CoQ reductase (complex I) deficiency in Parkinson's disease," Journal of Neurochemistry, vol. 55, no. 6, pp. 2142-2145, 1990.

[8] W. D. Parker Jr., J. K. Parks, and R. H. Swerdlow, "Complex I deficiency in Parkinson's disease frontal cortex," Brain Research, vol. 1189, no. 1, pp. 215-218, 2008.

[9] D. T. Dexter, P. Jenner, A. H.V. Schapira, and C. D. Marsden, "Alterations in levels of iron, ferritin, and other trace metals in neurodegenerative diseases affecting the basal ganglia," Annals of Neurology, vol. 32, supplement, pp. S94-S100, 1992.

[10] V. M. Mann, J. M. Cooper, S. E. Daniel et al., "Complex I, iron, and ferritin in Parkinson's disease substantia nigra," Annals of Neurology, vol. 36, no. 6, pp. 876-881, 1994.

[11] A. H. V. Schapira, "Oxidative stress in Parkinson's disease," Neuropathology and Applied Neurobiology, vol. 21, no. 1, pp. 3-9, 1995.

[12] A. D. Owen, A. H. V. Schapira, P. Jenner, and C. D. Marsden, "Oxidative stress and Parkinson's disease," Annals of the New York Academy of Sciences, vol. 786, pp. 217-223, 1996.

[13] M. Gu, A. D. Owen, S. E. K. Toffa et al., "Mitochondrial function, GSH and iron in neurodegeneration and Lewy body diseases," Journal of the Neurological Sciences, vol. 158, no. 1, pp. 24-29, 1998.

[14] C. W. Olanow, "A radical hypothesis for neurodegeneration," Trends in Neurosciences, vol. 16, no. 11, pp. 439-444, 1993.

[15] J. A. Morgan-Hughes, M. G. Sweeney, J. M. Cooper et al., "Mitochondrial DNA (mtDNA) diseases: correlation of genotype to phenotype," Biochimica et Biophysica Acta, vol. 1271, no. 1, pp. 135-140, 1995.

[16] D. Thyagarajan, S. Bressman, C. Bruno et al., "A novel mitochondrial 12SrRNA point mutation in parkinsonism, deafness, and neuropathy," Annals of Neurology, vol. 48, no. 5, pp. 730-736, 2000.

[17] J. A. Morgan-Hughes, A. H. V. Schapira, J. M. Cooper, and J. B. Clark, "Molecular defects of NADH-ubiquinone oxidoreductase (Complex I) in mitochondrial diseases," Journal of Bioenergetics and Biomembranes, vol. 20, no. 3, pp. 365-382, 1988.

[18] A. H. V. Schapira, J. M. Cooper, J. A. Morgan-Hughes et al., "Molecular basis of mitochondrial myopathies: polypeptide analysis in complex-I deficiency," Lancet, vol. 1, no. 8584, pp. 500-503, 1988.

[19] M. G. Hanna, I. P. Nelson, S. Rahman et al., "Cytochrome c oxidase deficiency associated with the first stop-codon point mutation in human mtDNA," American Journal of Human Genetics, vol. 63, no. 1, pp. 29-36, 1998.

[20] S. Rahman, J. W. Taanman, J. M. Cooper et al., "A missense mutation of cytochrome oxidase subunit II causes defective assembly and myopathy," American Journal of Human Genetics, vol. 65, no. 4, pp. 1030-1039, 1999.

[21] M. Mancuso, M. Filosto, S. J. Oh, and S. DiMauro, "A novel polymerase $\gamma$ mutation in a family with ophthalmoplegia, neuropathy, and parkinsonism," Archives of Neurology, vol. 61, no. 11, pp. 1777-1779, 2004.

[22] G. Davidzon, P. Greene, M. Mancuso et al., "Early-onset familial parkinsonism due to POLG mutations," Annals of Neurology, vol. 59, no. 5, pp. 859-862, 2006.

[23] P. Luoma, A. Melberg, J. O. Rinne et al., "Parkinsonism, premature menopause, and mitochondrial DNA polymerase $\gamma$ mutations: clinical and molecular genetic study," Lancet, vol. 364, no. 9437, pp. 875-882, 2004.

[24] A. A. M. Morris, J. W. Taanman, J. Blake et al., "Liver failure associated with mitochondrial DNA depletion," Journal of Hepatology, vol. 28, no. 4, pp. 556-563, 1998.

[25] J. W. Taanman, S. Rahman, A. T. Pagnamenta et al., "Analysis of mutant DNA polymerase $\gamma$ in patients with mitochondrial DNA depletion," Human Mutation, vol. 30, no. 2, pp. 248254, 2009.

[26] J. W. Taanman and A. H. V. Schapira, "Analysis of the trinucleotide CAG repeat from the DNA polymerase $\gamma$ gene (POLG) in patients with Parkinson's disease," Neuroscience Letters, vol. 376, no. 1, pp. 56-59, 2005.

[27] G. Hudson, A. M. Schaefer, R. W. Taylor et al., "Mutation of the linker region of the polymerase $\gamma$-1 (POLG1) gene associated with progressive external ophthalmoplegia and parkinsonism," Archives of Neurology, vol. 64, no. 4, pp. 553557, 2007.

[28] J. M. Cooper, V. M. Mann, and A. H. V. Schapira, "Analyses of mitochondrial respiratory chain function and mitochondrial DNA deletion in human skeletal muscle: effect of ageing," Journal of the Neurological Sciences, vol. 113, no. 1, pp. 9198, 1992.

[29] V. M. Mann, J. M. Cooper, and A. H. V. Schapira, "Quantitation of a mitochondrial DNA deletion in Parkinson's disease," FEBS Letters, vol. 299, no. 3, pp. 218-222, 1992.

[30] Y. Kraytsberg, E. Kudryavtseva, A. C. McKee, C. Geula, N. W. Kowall, and K. Khrapko, "Mitochondrial DNA deletions are abundant and cause functional impairment in aged human substantia nigra neurons," Nature Genetics, vol. 38, no. 5, pp. 518-520, 2006.

[31] A. Bender, K. J. Krishnan, C. M. Morris et al., "High levels of mitochondrial DNA deletions in substantia nigra neurons in aging and Parkinson disease," Nature Genetics, vol. 38, no. 5, pp. 515-517, 2006.

[32] C. S. Chan, J. N. Guzman, E. Ilijic et al., "“Rejuvenation” protects neurons in mouse models of Parkinson's disease," Nature, vol. 447, no. 7148, pp. 1081-1086, 2007.

[33] D. J. Surmeier, J. N. Guzman, and J. Sanchez-Padilla, "Calcium, cellular aging, and selective neuronal vulnerability in Parkinson's disease," Cell Calcium, vol. 47, no. 2, pp. 175-182, 2010.

[34] R. H. Swerdlow, J. K. Parks, D. S. Cassarino et al., "Biochemical analysis of cybrids expressing mitochondrial DNA 
from Contursi kindred Parkinson's subjects," Experimental Neurology, vol. 169, no. 2, pp. 479-485, 2001.

[35] M. K. Borland, K. P. Mohanakumar, J. D. Rubinstein et al., "Relationships among molecular genetic and respiratory properties of Parkinson's disease cybrid cells show similarities to Parkinson's brain tissues," Biochimica et Biophysica Acta, vol. 1792, no. 1, pp. 68-74, 2009.

[36] P. A. Trimmer, R. H. Swerdlow, J. K. Parks et al., "Abnormal mitochondrial morphology in sporadic Parkinson's and Alzheimer's disease cybrid cell lines," Experimental Neurology, vol. 162, no. 1, pp. 37-50, 2000.

[37] M. Gu, J. M. Cooper, J. W. Taanman, and A. H. V. Schapira, "Mitochondrial DNA transmission of the mitochondrial defect in Parkinson's disease," Annals of Neurology, vol. 44, no. 2, pp. 177-186, 1998.

[38] E. M. Valente, P. M. Abou-Sleiman, V. Caputo et al., "Hereditary early-onset Parkinson's disease caused by mutations in PINK1," Science, vol. 304, no. 5674, pp. 1158-1160, 2004.

[39] C. A. Gautier, T. Kitada, and J. Shen, "Loss of PINK1 causes mitochondrial functional defects and increased sensitivity to oxidative stress," Proceedings of the National Academy of Sciences of the United States of America, vol. 105, no. 32, pp. 11364-11369, 2008.

[40] S. Gandhi, A. Wood-Kaczmar, Z. Yao et al., "PINK1associated Parkinson's disease is caused by neuronal vulnerability to calcium-induced cell death," Molecular Cell, vol. 33, no. 5, pp. 627-638, 2009.

[41] M. E. Gegg, J. M. Cooper, A. H. V. Schapira, and J. W. Taanman, "Silencing of PINK1 expression affects mitochondrial DNA and oxidative phosphorylation in DOPAMINERGIC cells," PLoS ONE, vol. 4, no. 3, article e4756, 2009.

[42] H. H. Hoepken, S. Gispert, B. Morales et al., "Mitochondrial dysfunction, peroxidation damage and changes in glutathione metabolism in PARK6," Neurobiology of Disease, vol. 25, no. 2, pp. 401-411, 2007.

[43] C. Piccoli, A. Sardanelli, R. Scrima et al., "Mitochondrial respiratory dysfunction in familiar Parkinsonism associated with PINK1 mutation," Neurochemical Research, vol. 33, no. 12 , pp. 2565-2574, 2008.

[44] A. Grünewald, M. E. Gegg, J. W. Taanman et al., "Differential effects of PINK1 nonsense and missense mutations on mitochondrial function and morphology," Experimental Neurology, vol. 219, no. 1, pp. 266-273, 2009.

[45] S. Gispert, F. Ricciardi, A. Kurz et al., "Parkinson phenotype in aged PINK1-deficient mice is accompanied by progressive mitochondrial dysfunction in absence of neurodegeneration," PLoS ONE, vol. 4, no. 6, article e5777, 2009.

[46] E. M. Valente, S. Salvi, T. Ialongo et al., "PINK1 mutations are associated with sporadic early-onset Parkinsonism," Annals of Neurology, vol. 56, no. 3, pp. 336-341, 2004.

[47] Y. Hatano, Y. Li, K. Sato et al., "Novel PINK1 mutations in early-onset parkinsonism," Annals of Neurology, vol. 56, no. 3, pp. 424-427, 2004.

[48] C. F. Rohé, P. Montagna, G. Breedveld, P. Cortelli, B. A. Oostra, and V. Bonifati, "Homozygous PINK1 C-terminus mutation causing early-onset parkinsonism," Annals of Neurology, vol. 56, no. 3, pp. 427-431, 2004.

[49] R. A. Capaldi, M. F. Marusich, and J. W. Taanman, "Mammalian cytochrome-c oxidase: characterization of enzyme and immunological detection of subunits in tissue extracts and whole cells," Methods in Enzymology, vol. 260, pp. 117132, 1995.
[50] J. W. Taanman, M. D. Burton, M. F. Marusich, N. G. Kennaway, and R. A. Capaldi, "Subunit specific monoclonal antibodies show different steady-state levels of various cytochrome-c oxidase subunits in chronic progressive external ophthalmoplegia," Biochimica et Biophysica Acta, vol. 1315, no. 3, pp. 199-207, 1996.

[51] B. Schulenberg, R. Aggeler, J. M. Beechem, R. A. Capaldi, and W. F. Patton, "Analysis of steady-state protein phosphorylation in mitochondria using a novel fluorescent phosphosensor dye," Journal of Biological Chemistry, vol. 278, no. 29, pp. 27251-27255, 2003.

[52] R. Chen, I. M. Fearnley, S. Y. Peak-Chew, and J. E. Walker, "The phosphorylation of subunits of complex i from bovine heart mitochondria," Journal of Biological Chemistry, vol. 279, no. 25, pp. 26036-26045, 2004.

[53] J. Murray, M. F. Marusich, R. A. Capaldi, and R. Aggeler, "Focused proteomics: monoclonal antibody-based isolation of the oxidative phosphorylation machinery and detection of phosphoproteins using a fluorescent phosphoprotein gel stain," Electrophoresis, vol. 25, no. 15, pp. 2520-2525, 2004.

[54] B. Schulenberg, T. N. Goodman, R. Aggeler, R. A. Capaldi, and W. F. Patton, "Characterization of dynamic and steadystate protein phosphorylation using a fluorescent phosphoprotein gel stain and mass spectrometry," Electrophoresis, vol. 25, no. 15, pp. 2526-2532, 2004.

[55] T. Kitada, S. Asakawa, N. Hattori, H. Matsumine, Y. Yamamura, and S. Minoshima, "Mutations in the parkin gene cause autosomal recessive juvenile parkinsonism," Nature, vol. 392, no. 6676, pp. 605-608, 1998.

[56] H. Takahashi, E. Ohama, S. Suzuki et al., "Familial juvenile parkinsonism: clinical and pathologic study in a family," Neurology, vol. 44, no. 3 I, pp. 437-441, 1994.

[57] M. Farrer, P. Chan, R. Chen et al., "Lewy bodies and parkinsonism in families with parkin mutations," Annals of Neurology, vol. 50, no. 3, pp. 293-300, 2001.

[58] P. P. Pramstaller, M. G. Schlossmacher, T. S. Jacques et al., "Lewy body Parkinson's disease in a large pedigree with 77 Parkin mutation carriers," Annals of Neurology, vol. 58, no. 3, pp. 411-422, 2005.

[59] N. Hattori, T. Kitada, H. Matsumine et al., "Molecular genetic analysis of a novel Parkin gene in Japanese families with autosomal recessive juvenile parkinsonism: evidence for variable homozygous deletions in the Parkin gene in affected individuals," Annals of Neurology, vol. 44, no. 6, pp. 935-941, 1998.

[60] N. Abbas, C. B. Lücking, S. Ricard et al., "A wide variety of mutations in the parkin gene are responsible for autosomal recessive parkinsonism in Europe," Human Molecular Genetics, vol. 8, no. 4, pp. 567-574, 1999.

[61] Y. Wang, L. N. Clark, E. D. Louis et al., "Risk of Parkinson disease in carriers of Parkin mutations: estimation using the kin-cohort method," Archives of Neurology, vol. 65, no. 4, pp. 467-474, 2008.

[62] A. West, M. Periquet, S. Lincoln et al., "Complex relationship between Parkin mutations and Parkinson disease," American Journal of Medical Genetics, vol. 114, no. 5, pp. 584-591, 2002.

[63] H. Shimura, N. Hattori, S. I. Kubo et al., "Familial Parkinson disease gene product, parkin, is a ubiquitin-protein ligase," Nature Genetics, vol. 25, no. 3, pp. 302-305, 2000.

[64] Y. Zhang, J. Gao, K. K. K. Chung, H. Huang, V. L. Dawson, and T. M. Dawson, "Parkin functions as an E2-dependent ubiquitin-protein ligase and promotes the degradation of the synaptic vesicle-associated protein, CDCrel-1,” Proceedings 
of the National Academy of Sciences of the United States of America, vol. 97, no. 24, pp. 13354-13359, 2000.

[65] L. S. Chin, J. A. Olzmann, and L. Li, "Parkin-mediated ubiquitin signalling in aggresome formation and autophagy," Biochemical Society Transactions, vol. 38, no. 1, pp. 144-149, 2010.

[66] J. J. Palacino, D. Sagi, M. S. Goldberg et al., "Mitochondrial dysfunction and oxidative damage in parkin-deficient mice," Journal of Biological Chemistry, vol. 279, no. 18, pp. 18614 18622, 2004.

[67] J. C. Greene, A. J. Whitworth, I. Kuo, L. A. Andrews, M. B. Feany, and L. J. Pallanck, "Mitochondrial pathology and apoptotic muscle degeneration in Drosophila parkin mutants," Proceedings of the National Academy of Sciences of the United States of America, vol. 100, no. 7, pp. 4078-4083, 2003.

[68] F. Darios, O. Corti, C. B. Lücking et al., "Parkin prevents mitochondrial swelling and cytochrome $c$ release in mitochondria-dependent cell death," Human Molecular Genetics, vol. 12, no. 5, pp. 517-526, 2003.

[69] M. Muftuoglu, B. Elibol, O. Dalmizrak et al., "Mitochondrial complex I and IV activities in leukocytes from patients with parkin mutations," Movement Disorders, vol. 19, no. 5, pp. 544-548, 2004.

[70] H. Mortiboys, K. J. Thomas, W. J. H. Koopman et al., "Mitochondrial function and morphology are impaired in parkin-mutant fibroblasts," Annals of Neurology, vol. 64, no. 5, pp. 555-565, 2008.

[71] A. Grünewald, L. Voges, A. Rakovic, M. Kasten, H. Vandebona, and C. Hemmelmann, "Mutant parkin impairs mitochondrial function and morphology in human fibroblasts," PLoS ONE, vol. 5, no. 9, article e12962, 2010.

[72] E. Junn, W. H. Jang, X. Zhao, B. S. Jeong, and M. M. Mouradian, "Mitochondrial localization of DJ-1 leads to enhanced neuroprotection," Journal of Neuroscience Research, vol. 87, no. 1, pp. 123-129, 2009.

[73] J. Fan, H. Ren, N. Jia et al., "DJ-1 decreases Bax expression through repressing p53 transcriptional activity," Journal of Biological Chemistry, vol. 283, no. 7, pp. 4022-4030, 2008.

[74] N. Zhong and J. Xu, "Synergistic activation of the human MnSOD promoter by DJ-1 and PGC- $1 \alpha$ : regulation by SUMOylation and oxidation," Human Molecular Genetics, vol. 17, no. 21, pp. 3357-3367, 2008.

[75] M. P. Van Der Brug, J. Blackinton, J. Chandran et al., "RNA binding activity of the recessive parkinsonism protein DJ-1 supports involvement in multiple cellular pathways," Proceedings of the National Academy of Sciences of the United States of America, vol. 105, no. 29, pp. 10244-10249, 2008.

[76] J. N. Guzman, J. Sanchez-Padilla, D. Wokosin et al., "Oxidant stress evoked by pacemaking in dopaminergic neurons is attenuated by DJ-1," Nature, vol. 468, no. 7324, pp. 696-700, 2010.

[77] S. Batelli, D. Albani, R. Rametta et al., "DJ-1 modulates $\alpha$ synuclein aggregation state in a cellular model of oxidative stress: relevance for Parkinson's Disease and involvement of HSP70," PLoS ONE, vol. 3, no. 4, article e1884, 2008.

[78] M. H. Polymeropoulos, C. Lavedan, E. Leroy et al., "Mutation in the $\alpha$-synuclein gene identified in families with Parkinson's disease," Science, vol. 276, no. 5321, pp. 2045-2047, 1997.

[79] R. Krüger, W. Kuhn, T. Müller et al., "Ala30Pro mutation in the gene encoding $\alpha$-synuclein in Parkinson's disease," Nature Genetics, vol. 18, no. 2, pp. 106-108, 1998.
[80] A. B. Singleton, M. Farrer, J. Johnson et al., " $\alpha$-synuclein locus triplication causes Parkinson's disease," Science, vol. 302, no. 5646, p. 841, 2003.

[81] M. Farrer, J. Kachergus, L. Forno et al., "Comparison of kindreds with Parkinsonism and $\alpha$-synuclein genomic multiplications," Annals of Neurology, vol. 55, no. 2, pp. 174179, 2004.

[82] J. J. Zarranz, J. Alegre, J. C. Gómez-Esteban et al., "The new mutation, E46K, of $\alpha$-synuclein causes Parkinson and lewy body dementia," Annals of Neurology, vol. 55, no. 2, pp. 164173, 2004.

[83] M. G. Spillantini, M. L. Schmidt, V. M. Y. Lee, J. Q. Trojanowski, R. Jakes, and M. Goedert, " $\alpha$-synuclein in Lewy bodies," Nature, vol. 388, no. 6645, pp. 839-840, 1997.

[84] W. W. Li, R. Yang, J. C. Guo et al., "Localization of $\alpha$-synuclein to mitochondria within midbrain of mice," NeuroReport, vol. 18, no. 15, pp. 1543-1546, 2007.

[85] K. Nakamura, V. M. Nemani, E. K. Wallender, K. Kaehlcke, M. Ott, and R. H. Edwards, "Optical reporters for the conformation of $\alpha$-synuclein reveal a specific interaction with mitochondria," Journal of Neuroscience, vol. 28, no. 47, pp. 12305-12317, 2008.

[86] G. Liu, C. Zhang, J. Yin et al., " $\alpha$-Synuclein is differentially expressed in mitochondria from different rat brain regions and dose-dependently down-regulates complex I activity," Neuroscience Letters, vol. 454, no. 3, pp. 187-192, 2009.

[87] L. Devi, V. Raghavendran, B. M. Prabhu, N. G. Avadhani, and H. K. Anandatheerthavarada, "Mitochondrial import and accumulation of $\alpha$-synuclein impair complex I in human dopaminergic neuronal cultures and Parkinson disease brain," Journal of Biological Chemistry, vol. 283, no. 14, pp. 9089-9100, 2008.

[88] K. Banerjee, M. Sinha, C. L. L. Pham et al., “ $\alpha$-synuclein induced membrane depolarization and loss of phosphorylation capacity of isolated rat brain mitochondria: implications in Parkinson's disease," FEBS Letters, vol. 584, no. 8, pp. 1571-1576, 2010.

[89] F. Kamp, N. Exner, A. K. Lutz et al., "Inhibition of mitochondrial fusion by $\alpha$-synuclein is rescued by PINK1, Parkin and DJ-1," EMBO Journal, vol. 29, no. 20, pp. 35713589, 2010.

[90] L. J. Martin, Y. Pan, A. C. Price et al., "Parkinson's disease $\alpha$-synuclein transgenic mice develop neuronal mitochondrial degeneration and cell death," Journal of Neuroscience, vol. 26, no. 1, pp. 41-50, 2006.

[91] K. Y. Chau, H. L. Ching, A. H. V. Schapira, and J. M. Cooper, "Relationship between alpha synuclein phosphorylation, proteasomal inhibition and cell death: relevance to Parkinson's disease pathogenesis," Journal of Neurochemistry, vol. 110, no. 3, pp. 1005-1013, 2009.

[92] G. Krebiehl, S. Ruckerbauer, L. F. Burbulla et al., "Reduced basal autophagy and impaired mitochondrial dynamics due to loss of Parkinson's disease-associated protein DJ-1," PLoS ONE, vol. 5, no. 2, article e9367, 2010.

[93] I. Irrcher, H. Aleyasin, E. L. Seifert et al., "Loss of the Parkinson's disease-linked gene DJ-1 perturbs mitochondrial dynamics," Human Molecular Genetics, vol. 19, no. 19, pp. 3734-3746, 2010.

[94] A. K. Lutz, N. Exner, M. E. Fett et al., "Loss of parkin or PINK1 function increases Drp1-dependent mitochondrial fragmentation," Journal of Biological Chemistry, vol. 284, no. 34, pp. 22938-22951, 2009. 
[95] A. Sandebring, K. J. Thomas, A. Beilina et al., "Mitochondrial alterations in PINK1 deficient cells are influenced by calcineurin-dependent dephosphorylation of dynaminrelated protein 1," PLoS ONE, vol. 4, no. 5, article e5701, 2009.

[96] H. Deng, M. W. Dodson, H. Huang, and M. Guo, "The Parkinson's disease genes pink1 and parkin promote mitochondrial fission and/or inhibit fusion in Drosophila," Proceedings of the National Academy of Sciences of the United States of America, vol. 105, no. 38, pp. 14503-14508, 2008.

[97] Y. Yang, Y. Ouyang, L. Yang et al., "Pink1 regulates mitochondrial dynamics through interaction with the fission/fusion machinery," Proceedings of the National Academy of Sciences of the United States of America, vol. 105, no. 19, pp. 7070-7075, 2008.

[98] A. C. Poole, R. E. Thomas, L. A. Andrews, H. M. McBride, A. J. Whitworth, and L. J. Pallanck, "The PINK1/Parkin pathway regulates mitochondrial morphology," Proceedings of the National Academy of Sciences of the United States of America, vol. 105, no. 5, pp. 1638-1643, 2008.

[99] R. K. Dagda, S. J. Cherra III, S. M. Kulich, A. Tandon, D. Park, and C. T. Chu, "Loss of PINK1 function promotes mitophagy through effects on oxidative stress and mitochondrial fission," Journal of Biological Chemistry, vol. 284, no. 20, pp. 13843-13855, 2009.

[100] C. Vives-Bauza, C. Zhou, Y. Huang et al., "PINK1-dependent recruitment of Parkin to mitochondria in mitophagy," Proceedings of the National Academy of Sciences of the United States of America, vol. 107, no. 1, pp. 378-383, 2010.

[101] C. T. Chu, "A pivotal role for PINK1 and autophagy in mitochondrial quality control: implications for Parkinson disease," Human Molecular Genetics, vol. 19, no. 1, pp. R28R37, 2010.

[102] D. Narendra, A. Tanaka, D. F. Suen, and R. J. Youle, "Parkin is recruited selectively to impaired mitochondria and promotes their autophagy," Journal of Cell Biology, vol. 183, no. 5, pp. 795-803, 2008.

[103] Y. Kim, J. Park, S. Kim et al., "PINK1 controls mitochondrial localization of Parkin through direct phosphorylation," Biochemical and Biophysical Research Communications, vol. 377, no. 3, pp. 975-980, 2008.

[104] D. P. Narendra, S. M. Jin, A. Tanaka et al., "PINK1 is selectively stabilized on impaired mitochondria to activate Parkin," PLoS Biology, vol. 8, no. 1, article e1000298, 2010.

[105] A. J. Whitworth and L. J. Pallanck, "The PINK1/Parkin pathway: a mitochondrial quality control system?” Journal of Bioenergetics and Biomembranes, vol. 41, no. 6, pp. 499-503, 2009.

[106] M. E. Gegg, J. M. Cooper, K.-Y. Chau, M. Rojo, A. H. V. Schapira, and J.-W. Taanman, "Mitofusin 1 and mitofusin 2 are ubiquitinated in a PINK1/parkin-dependent manner upon induction of mitophagy," Human Molecular Genetics, vol. 19, no. 24, pp. 4861-4870, 2010.

[107] K. J. Thomas, M. K. McCoy, J. Blackinton, A. Beilina, B. M. van der, and A. Sandebring, "DJ-1 acts in parallel to the PINK1/parkin pathway to control mitochondrial function and autophagy," Human Molecular Genetics, vol. 20, no. 1, pp. 40-50, 2010.

[108] L. Y. Hao, B. I. Giasson, and N. M. Bonini, "DJ-1 is critical for mitochondrial function and rescues PINK1 loss of function," Proceedings of the National Academy of Sciences of the United States of America, vol. 107, no. 21, pp. 9747-9752, 2010.
[109] H. Plun-Favreau, K. Klupsch, N. Moisoi et al., "The mitochondrial protease HtrA2 is regulated by Parkinson's diseaseassociated kinase PINK1," Nature Cell Biology, vol. 9, no. 11, pp. 1243-1252, 2007.

[110] K. M. Strauss, L. M. Martins, H. Plun-Favreau et al., "Loss of function mutations in the gene encoding Omi/HtrA2 in Parkinson's disease," Human Molecular Genetics, vol. 14, no. 15, pp. 2099-2111, 2005.

[111] V. Bogaerts, K. Nuytemans, J. Reumers et al., "Genetic variability in the mitochondrial serine protease HTRA2 contributes to risk for Parkinson disease," Human Mutation, vol. 29, no. 6, pp. 832-840, 2008.

[112] J. W. Pridgeon, J. A. Olzmann, L. S. Chin, and L. Li, "PINK1 protects against oxidative stress by phosphorylating mitochondrial chaperone TRAP1," PLoS Biology, vol. 5, no. 7, article e172, 2007.

[113] L. Alvarez-Erviti, M. C. Rodriguez-Oroz, J. M. Cooper et al., "Chaperone-mediated autophagy markers in Parkinson disease brains," Archives of Neurology, vol. 67, no. 12, pp. 1464-1472, 2010.

[114] R. Betarbet, T. B. Sherer, G. MacKenzie, M. Garcia-Osuna, A. V. Panov, and J. T. Greenamyre, "Chronic systemic pesticide exposure reproduces features of Parkinson's disease," Nature Neuroscience, vol. 3, no. 12, pp. 1301-1306, 2000.

[115] M. Höllerhage, A. Matusch, P. Champy et al., "Natural lipophilic inhibitors of mitochondrial complex I are candidate toxins for sporadic neurodegenerative tau pathologies," Experimental Neurology, vol. 220, no. 1, pp. 133-142, 2009.

[116] A. H. V. Schapira, "Complex I: inhibitors, inhibition and neurodegeneration," Experimental Neurology, vol. 224, no. 2, pp. 331-335, 2010.

[117] F. Kamel, C. M. Tanner, D. M. Umbach et al., "Pesticide exposure and self-reported Parkinson's disease in the agricultural health study," American Journal of Epidemiology, vol. 165, no. 4, pp. 364-374, 2007.

[118] M. Gu, M. Irvani, J. M. Cooper, D. King, P. Jenner, and A. H. V. Schapira, "Pramipexole protects against apoptotic cell death by non-dopaminergic mechanisms," Journal of Neurochemistry, vol. 91, no. 5, pp. 1075-1081, 2004.

[119] C. W. Shults, D. Oakes, K. Kieburtz et al., "Effects of coenzyme Q in early Parkinson disease: evidence of slowing of the functional decline," Archives of Neurology, vol. 59, no. 10, pp. 1541-1550, 2002.

[120] K. Kieburtz, B. Ravina, W. R. Galpern et al., "A randomized clinical trial of coenzyme Q10 and GPI-1485 in early Parkinson disease," Neurology, vol. 68, no. 1, pp. 20-28, 2007. 


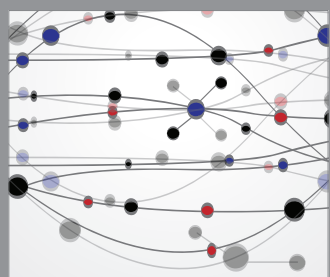

The Scientific World Journal
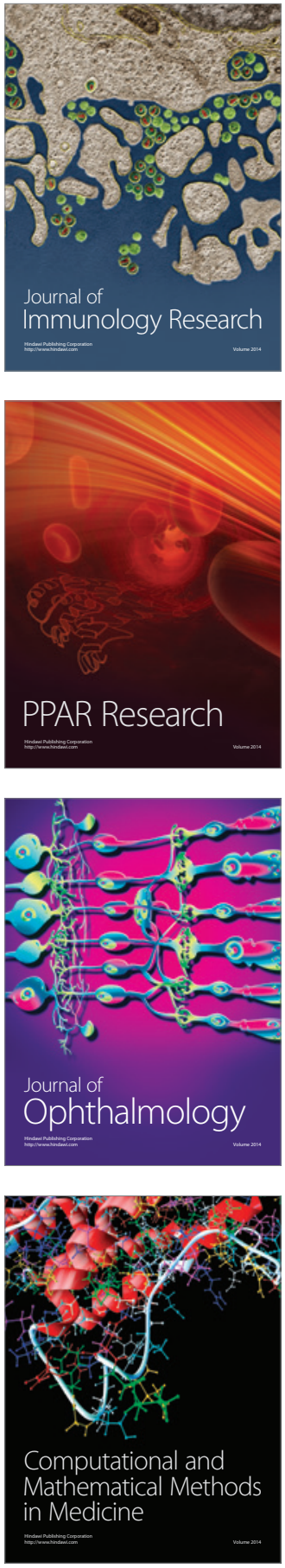

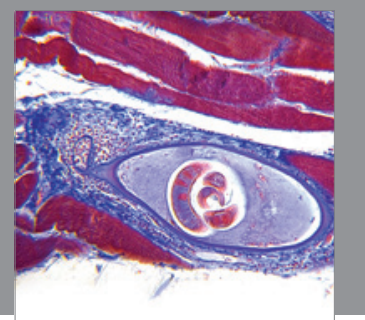

Gastroenterology

Research and Practice
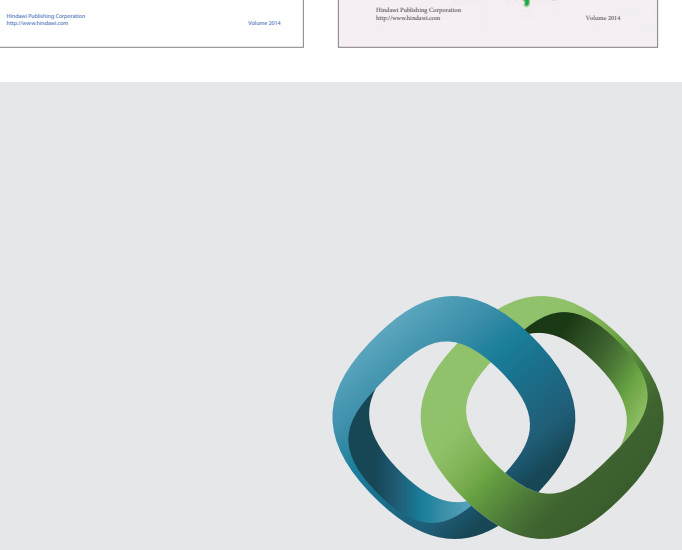

\section{Hindawi}

Submit your manuscripts at

http://www.hindawi.com
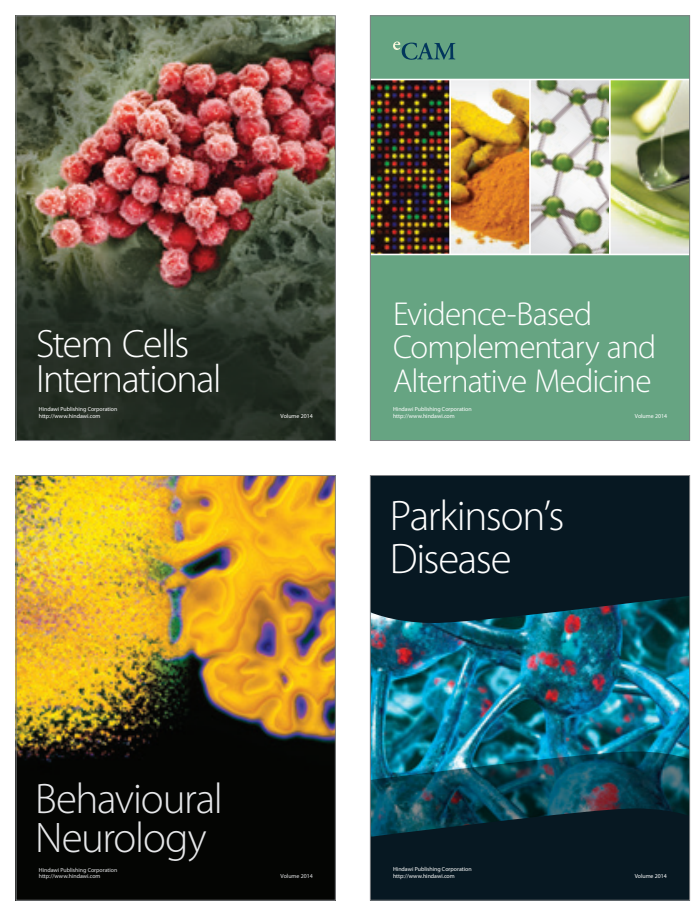

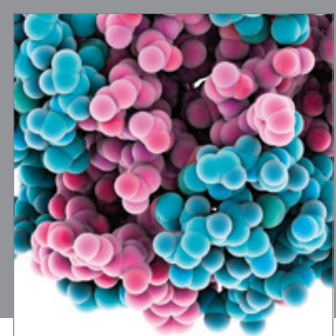

Journal of
Diabetes Research

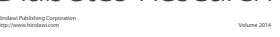

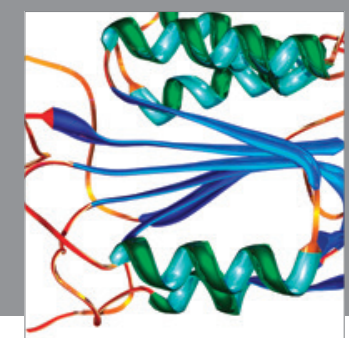

Disease Markers
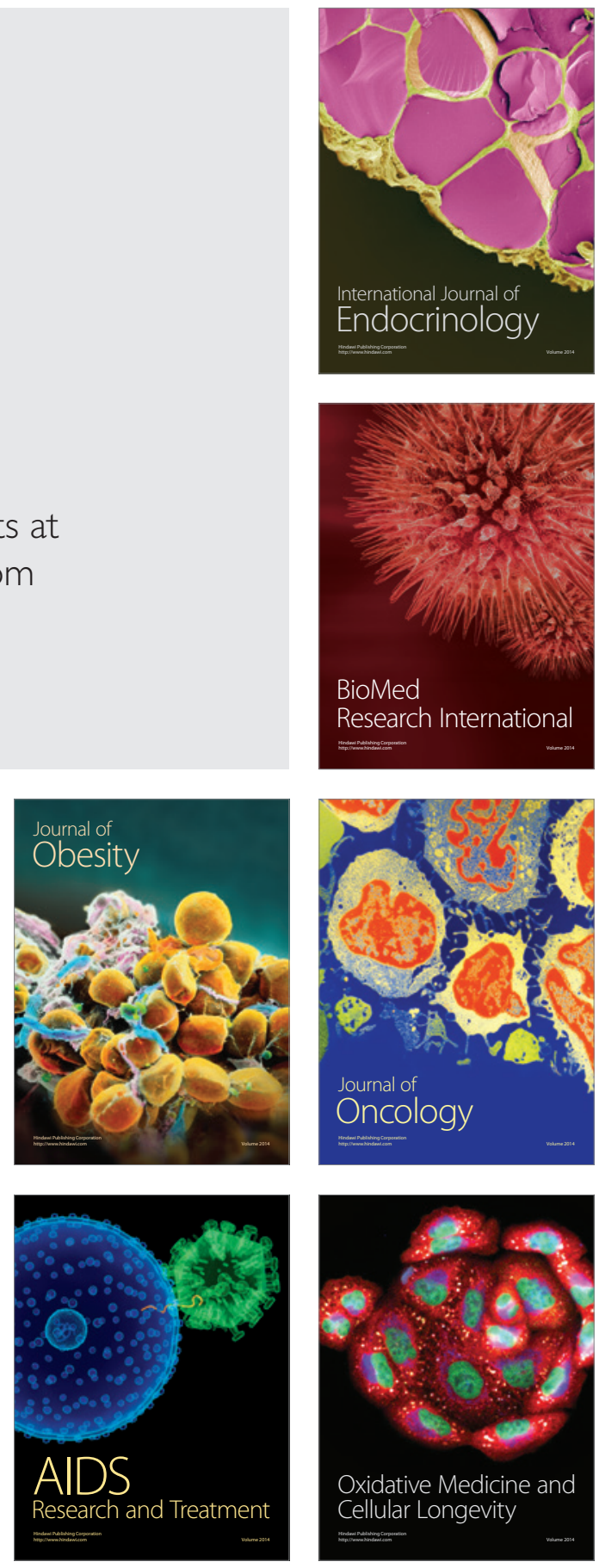